\title{
ENVIRONMENTAL EDUCATION FOR SUSTAINABLE DEVELOPMENT OF UNESCO ASSOCIATED SCHOOLS PROJECT NETWORK IN JAPAN
}

\author{
Yayoi Kodama \\ University of Kitakyushu (Japan)
}

\begin{abstract}
Environmental education for sustainable development in Japan has developed rapidly in recent years. Focusing on formal education, schools called "UNESCO School" play a leading role in environmental education for sustainable development. The school network approved by UNESCO was for promoting international understanding education, but it is currently positioned as an association of schools promoting ESD. This paper describes the establishment and development of the UNESCO School and focuses on the practices of the schools which focuses on environmental education as ESD.
\end{abstract}

\section{INTRODUCTION}

"Sustainable Development Targets (SDGs)" (2016 - 2030), the core objective of 2030 Agenda adopted in 2015, is the goal to deal with issues of MDGs that were not achieved with. To achieve these targets, it is necessary to involve various stakeholders, and it is also required a partnership of stakeholders that take part in. In order to promote efforts to achieve the goal, human resource development is essential, and environmental education plays a major role.

Environmental education is positioned as a key player for promoting education for sustainable development (ESD), and in this sense it should be noted more and more in future. There is a great concern for ESD in the ed- ucational world of Japan, and various challenges of practices have been carried out. However, understanding of Education for Sustainable Development has not spread well yet in this country. The recognition about ESD is not so high except for educator and people concerned. For example, according to a Cabinet Office survey (2014) conducted in the final year of 'the Decade of ESD,' there were many people who said they do not know about ESD (79.1\%). And nearly half of the respondents answered that 'it is hard to imagine concrete activities' (44.0\%). Meanwhile, in the research report, respondents are expecting schools as a place for students to learn 'sustainable development' and are also interested in nurturing the next generation with knowledge and skills for 'sustainability.' 
How is environmental education being promoted for sustainable development in today's Japan? This paper focuses on 'UNESCO School (ASPNet).' The network of schools that approved by UNESCO began as a network for promoting international understanding education. Currently, however, the network is positioned as a community of schools promoting ESD. This paper describes the development of environmental education in Japan since 1970s. And it focuses on the establishment and development of the UNESCO School, especially the time when it is positioned as the base of ESD. Besides, this paper also refers to the practices of those schools which focuses on environmental education as ESD.

\section{DEVELOPMENT OF \\ ENVIRONMENTAL EDUCATION IN JAPAN}

Although environmental education in Japan has achieved remarkable results, it has not spread smoothly.

The word 'Kankyou Kyouiku (Environmental Education)' appeared in 1970. It was used as a translation of 'Environmental Education' in the column of newspaper introducing advanced educational practices in the United States (Satoshi Ichikawa, 2017). However, this word initially used in almost the same as 'Kougai Kyouiku (Education on environmental pollution).' It is closely related the history of the generation of environmental pollution and its solution. In the process of solution, it was essential for citizens to learn about environmental pollution and to work with companies and governments for antipollution measures. The remarkable economic growth in the 1950s and 1960s has resulted in destruction of the natural environment and significant health damage while people who live in Japan became enriched. People interested in environmental pollution problems learned about the mechanism of them and began to demand regulations for companies and governments. The birth of the word 'Kankyou Kyouiku' was the same year as the enactment and revision of 14 environmental laws.

High attention is focused on the deterioration of the natural environment in many countries including Japan. The Stockholm Conference was held in 1972 and a recommendation on the environmental protection was adopted. Environmental education was positioned as one of the issues to be practiced internationally, and then UNESCO was expected to take the initiative to promote environmental education. And the declaration adopted at the Tbilisi Conference held in 1977 is still regarded as the basic principle of environmental education.

In the early 1970s, the term 'environmental education' was mainly used by stakeholders in science education in Japan. And the word was meant to learn about environmental pollution in the subject (science). Eventually, with the growing interest in international environmental education, environmental education came to be understood as promoting learning of human-environmental relationships and learning about environmental quality. Viewpoints on environmental education were intro- 
duced into "Gakusyu Shidou Youryo (the curriculum guidelines)" of elementary school and junior high school, and development of environmental education was expected. However the environmental education in the 1980s was rather lowered.

One of the major factors was 'the Declaration of Termination of Environmental Pollution Problems and Environmental Problems' issued by the Environment Agency. As a result of a lot of efforts, environmental pollution control progressed and realized the cleaning up of the environment. It was ironic result that the solution of environmental problems creates stagnation of environmental education. In addition, another serious problems such as bullying and school refusal had occurred in many schools and the countermeasures were given priority over the development of Environmental Education.

However, the interest in environmental issues had risen again and the new expansion of environmental education was created. One was concern for global environmental issues such as global warming and reduction of forests, which the effects spread to the global scale. The solution of them required international efforts and the issues were related to daily life and socioeconomic activities, so that change of awareness and behavior of everyone was required. The other was the consumption of resources and energy, and the increase of waste such as energy consumption due to electrification and disposable items. As with global environmental issues, these problems arising from changes in living due to urbanization had come to be required to change the awareness and behavior of each of the people in order to solve it.

Thus, environmental education in the 1990s focused on global environmental problems and environmental problems accompanying urbanization, but learning taken up the local environment familiar to children was increasing. The Ministry of Education, Culture, Sports, Science and Technology (MEXT) created guidebooks of environmental education for junior high schools and high schools in 1991 and for elementary school in 1992. Efforts on environmental education were promoted again at each school by referring to them. And practices incorporating observation, breeding of animals, cultivation of plants, environmental beautification and cleaning activities were carried out in order to compensate for 'shortage of experience',

When preparing the guidebook, the view of MEXT was that it would not establish a new subject for environmental education because of 'the wide range and multifaceted characteristics' of the environmental problems. In other words, environmental education was regarded as contents of learning to be taught through existing subjects and special activities. However, in the work for revision of the Curriculum guidelines, a new framework called 'the Period of Integrated Studies' was conceived and eventually it was positioned as a new framework to learn about 'environmen- 
tal issues' and international understanding.

Environmental education in Japan spread in the 1990s, but the framework of environmental education expands at the end of the 1990s. There was a desire for a 'sustainable society' based on 'sustainable development.'

The concept of 'sustainable development' was proposed as a concept to show that environmental conservation and development are not conflicting, but mutually complementary relationships. After the Johannesburg Summit in 1992, the concept of 'sustainable development' became common. The international turning point in environmental education was the Thessaloniki Conference in 1997. Documents adopted at this conference expressed environmental education as 'education for the environment and sustainability.' With the background of international trends, the report of the Chuou Kyouiku Shingikai (Central Council for Education) in 1999 clarified that it aimed to create a 'sustainable society.'

Environmental education and environmental learning are oriented toward realization of a sustainable society. In other words, all education and learning activities and processes for realizing a sustainable society can be said to be environmental education and environmental learning.

Table 1 'Sustainability' description in the guide on current Curriculum Guidelines

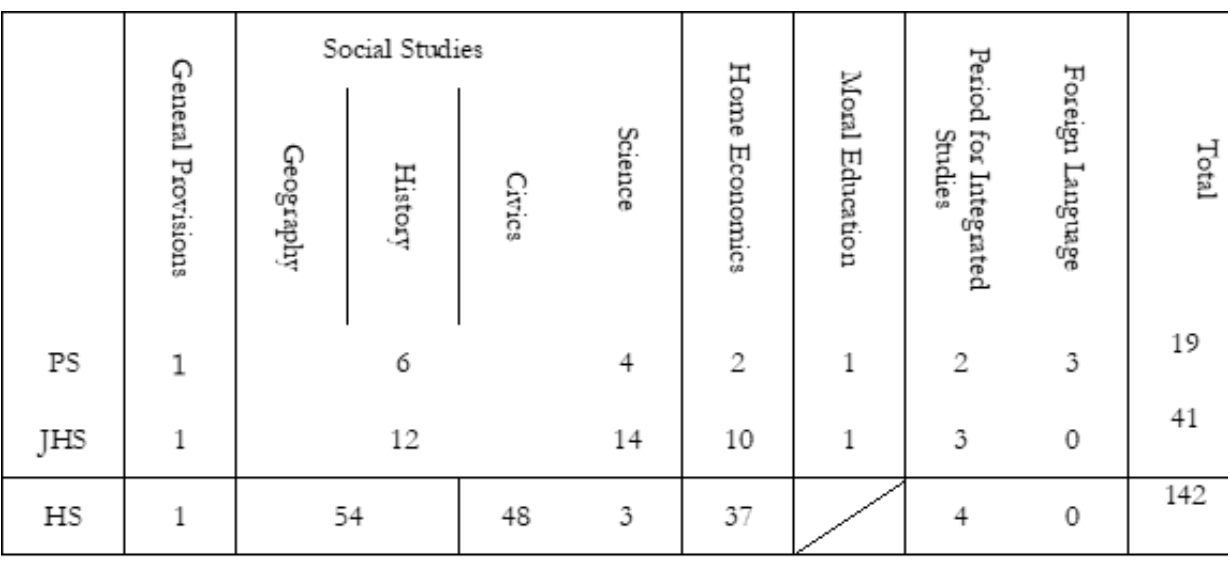

'Education for Sustainable Development (ESD)' was proposed as an education towards a sustainable society, 'Decade of ESD' (2005-2014) proposed by Japan was adopted by the General Assembly of the United Nations.
During this period, 'the Period of Integrated Studies' was established in the Curriculum guidelines, and 'learning about the environment around people' was exemplified as one of the learning topics. The Period of Integrated Studies 
implemented from 2002 is a new framework to learn about the environmental issues as one of the education for the 'sustainable society.' And it is also complementarily to other subjects, such as science and social studies.

The guides on Curriculum Guidelines are prepared for teachers. The words 'sustainable' are used for guide on current Curriculum guidelines of junior high school and high school, and for social studies, science and home economics (Table1). Social studies, science, home economics, and the Period of Integrated Studies are the subjects and activities to learn on 'sustainable development' and 'sustainable society.' This is a significant change in the sense that the guidelines gave the grounds for ESD. Each school can create the school curriculum for ESD based on the characteristics the area where the school is located.

In the Curriculum guidelines of elementary and junior high school revised in 2017, the term 'sustainable' is used and the framework of ESD is reflected.

How is environmental education at schools in Japan in recent years? In general, the practices of environmental education are carried out more frequently in elementary schools than in junior high school and high school. For environmental education that requires a comprehensive approach, it is probably easier for elementary school teachers that teach all subjects. In the case of junior high school and high school, the subjects for environmental education are social studies, science, home economics. Especially home economics is one of the best subject to learn about"environmentally-friendly life"because the subject has to learn 'consumption and the environment around people.' Typical activities of environmental education as experience activities are activities familiar with local nature and garbage separation and recycling activities. Furthermore, activities to raise animals and plants are often performed in elementary school.

According to Ichikawa (2016), more than $60 \%$ of elementary and junior high schools have environmental education plans to be implemented throughout the school. Ichikawa points out an interesting view on the practice of environmental education in the Period of Integrated Studies. In other words, there are differences in environmental education efforts by schools, and the difference is widening. The Period of Integrated Studies introduced in 2002 was established as a time to learn across the subjects. This was expected as a time to learn about 'environment' together with 'international understanding' and 'welfare,' and the number of schools that actually conducted environmental education increased. Today, especially in junior high schools, the environmental learning is not necessarily positioned as a major topic in the Period of Integrated Studies. And in elementary school, 'region' and 'environment' are treated as different topic. "Region" is to be understood as a topic to learn about traditions and history of the town where students live. From the viewpoint of promot- 
ing education about 'environment,' it is hard to say that the Period of Integrated Studies is fully utilized in many schools. Not all schools have positioned 'environment' as a major and basic topic.

\section{DePloyment of UNESCO AsSOCIATED SCHOOL (ASPNET) IN JAPAN}

What kinds of schools mainly conduct environmental education in Japan? Especially, what kinds of schools are promoting environmental education as ESD? In the case of Japan, those are schools called 'UNESCO School.' According to the Nippon Kyouiku Shinbun (Japanese Education Newspaper) in 2014, it was reported that the learning contents in the Period of Integrated Studies at the UNESCO School were as follows; environmental education (76.9\%), international understanding education (51.7\%), education for world heritage and regional culture (42.8\%). Schools which joined the network make 'environmental issues' one of the most important topics.

The schools began as a network for promoting international understanding education. Today, this network of schools is positioned as a community promoting ESD in formal education of Japan. The MEXT also sees the UNESCO School as the base of ESD in schools.

The UNESCO School, internationally known as the Associated Schools Project Network (ASPNet) in English, is the network between schools that make experimental educational at- tempts and exchanges to realize the philosophy of the UNESCO Charter. ASPNet started as an association of schools that conducted experimental trials of international understanding education, but today these schools are positioned as the base of ESD promotion. Currently, there are about 10,000 schools internationally affiliated with this network. In Japan, more than 1,000 schools are members (as of May 2017).

International ASPNet started from 33 schools in 1953. At first, ASPNet was a field for educational experiments for international understanding. Six Japanese junior high schools participated in the experiment, including the junior high school affiliated with Tokyo Education University and the junior high school affiliated with Hiroshima University in 1953, and 13 schools including high schools were joined in the following year. For a while, the Ministry of Education (at that time) had a close relationship with UNESCO. However, in the early 1970s the relationship with UNESCO changed and the Ministry of Education abolished the UNESCO Domestic Committee. However the Committee was established again and the UNESCO School, which was a federation of schools approved by UNES$\mathrm{CO}$, had made a dramatic network. And the rapid expansion of the UNESCO School involved the development of ESD in Japan.

Kodama (2015) divided the development of ESD in Japanese schools into three periods. They were the creation period from 2002, the experiment 
period from 2005, and the expansion period from 2008. At the time of the experiment, the characteristic practice was seen in the ESD of each school, and the practice of the Shinonome Elementary school in Tokyo, which developed the method of curriculum formation as "ESD Calendar", the basis of ESD in the current school. The Decade of the Education for sustainable development had started (2005-2014), and internationally, ASPNet became the core of ESD promotion. In Japan, ESD in schools rapidly expanded after the use of the word 'Construction of a sustainable society' in the Basic Education Promotion Plan and the Curriculum Guidelines in 2008. In the case of ESD efforts by individual schools, the remarkable cases appeared. They were the cases of some cities that all public schools in the city promoted ESD. And at this time, the UNESCO School contributed to expanding the popularization of ESD in schools. There were only 24 UNESCO Schools in 2007, however, the number of schools doubled since 2008. And in 2016 there were 1,037 schools, including 524 elementary schools, 255 junior high schools and 147 high schools. ESD rapidly expanded as a result of practices by local governments under educational policy rather than becoming popular due to the contents of education and its necessity.

Kobayashi (2014) pointed out important things in relation to the UNESCO School and ESD. As one of the significance of joining ASPNet, Kobayashi made reference to that students noticed the gap between 'serious problems in the international society' and 'serious problems in Japan.' The ability to notice the differences in viewpoint and adjust them is 'global competence.' Forming this capability is to nurture people with global perspectives. Participating in the UNESCO Associated School, utilizing the international network, and learning by students themselves lead to the formation of competency appropriate for modern society.

It is well-known that ESD is not limited only to environmental education. Looking at the conceptual diagram of ESD presented by the UNESCO Domestic Committee, it is necessary to learn how to interdisciplinary all relevant areas such as environment, international understanding, energy, disaster prevention, biodiversity, and climate change. In promoting ESD at school, it is often that the curriculum is organized with core the Period of Integrated Studies, which is a cross-disciplinary, because ESD cannot fully cope with only one subject.

The UNESCO Domestic Committee in Japan advises on how to approach ESD as follows, "the Manual of Promoting Education for Sustainable Development (First edition)" created in 2016.

ESD should be balanced in terms of school management, curriculum, improvement of school environment and cooperation with the community. It is important to make effective use of the Period Integrated Studies and special activities, and to plan cross-curriculum 
learning. And it is necessary for the school community to build cooperative relationships and to form the whole school cooperates, to form a climate of learning.

Practicing by the whole school is indispensable for more effective implementation of ESD. Then, under the leadership of the principal, teachers build mutual cooperative relationships and secure human resources in cooperation with community and parents. If human resources are not enough, school should cooperate with NPOs, companies, universities and others. The improvement of conditions require for promoting ESD. In addition, it constitutes the ESD curriculum based on the characteristics of the area and the developmental stage of the students. And it is necessary for teachers to be held workshops for ensuring teachers' learning. Promotion of ESD in schools is required to accumulate each such element.

There are schools promoting ESD while accumulating various elements in the UNESCO school. Chapter 3 focuses on the conditions of promotion of ESD in schools based on advanced school practices.

\section{ENVIronmental ESD Practice at UNESCO SCHOOL (ASPNET)}

"Guide to utilizing of teaching materials for ESD" was created in 2009 by the Asia-Pacific Central Cultural Centre for UNESCO (ACCJ). This was a guidebook created for schools and teachers trying to conduct ESD in schools, including examples of practices of schools. This book can be thought of as a guide for responding to the learning contents and methods for promoting ESD.

The book, which was created at the time the UNESCO School expand, was a comprehensive guidebook that also included learning contents to be included in ESD and methods of evaluation for 'academic ability' educated. There were practices of 13 schools in the book. Five were practices of junior high schools and eight were practices of elementary schools.

Focusing on elementary school practices, Most of the elementary schools adopted ESD typical learning topics such as environmental learning, international understanding, and disaster prevention. And some schools also adopted learning topics of welfare and food related to international understanding. Six of the eight elementary schools were members of the ASPNet. The other two schools were non-members of the network, but this book adopted practices that had been sustained and inherited for more than 10 years, regardless of the changes of principals and teachers. In Japan, in the case of public schools, principals and teachers do not always work for one school, but regularly transfer. This is one of the measures to ensure school standards. However, the system is rather a weak point in terms of characteristic educational continuity. It was because the idea of 'continuity of education' was reflected in that the guidebook included exam- 
ples of non-accessible schools. In other words, it was a value that ESD should not end in a transient way. The schools should continue their ESD practices even if teachers, students and their parents would change. And the thinking of continuity would be consistent with the concept of 'sustainability'

And this guidebook exemplified the annual plan, lesson plan, and outlines of the practices, and described what kind of ability the student formed. It was structured so that schools and teachers could think concretely in ESD practices.

In addition, this book contained not only the efforts of each school but also the information of cooperating agencies indispensable for practicing. For example, "eco Pica set" which was the practices of elementary school in Okayama City had cooperation / support of ESD Promotion Council, JICA staffs and University. This information was an important source for schools and teachers who were new to ESD because they could know how important it was to cooperate with any external institution to advance ESD.

The following two points were common to the eight cases appearing in the guidebook.

- These schools carried out ESD practices in the whole school and set the 'the Period Integrated Studies' as the core of curriculum

- These schools cooperated with external organizations and utilized human resources effectively.
Those viewpoints were important conditions for promoting ESD in schools. All members of school were involved ESD practices, in other words, by whole school approach school and teachers could create a systematic and ordered school curriculum for all students. This allowed students to continue learning for sustainable development while they were in school. In organization of the school curriculum, the core of curriculum was the Period of Integrated Studies. It played a role of organically connecting learning in other subjects. And students could experience subjective and deep learning. Furthermore, collaboration with external organizations was an indispensable element to organize diverse and concrete learning content and experience. The direct involvement of students with human resources that exceeded the knowledge and experiences of teachers guaranteed the rich and deeper learning opportunities for the students.

From the above viewpoints, this paper examines the advanced practices of environmental education for sustainable development in the UNESCO School in detail. One is the case of ESD practices based on the whole school approach that effectively utilizes the Period of Integrated Studies. The other is the case of ESD practices utilizing cooperation with external organizations.

Many schools, that conduct ESD in the whole school approach, have created the lists of 'ESD calendar.' The calendar is a school curriculum for Education for Sustainable Development, 
and it is a table of learning contents on sustainability for each grade. The tables are arranged topics from all subjects and activities, and connected the topics with lines. 'ESD calendar' is also the useful plan which is able to see the ties of each learning topics. Tejima (the present Principal of Yanagawa Elementary school), one of the inventors, explains the ESD calendar as follows. It is created so that any teacher in charge can imagine how to progress 'integrated learning.'

Tejima created an ESD calendar at Shinonome Elementary school when he was a principal at that school. And then he transferred to next school, and there, he has arranged ESD calendars with teachers. ESD calendars of some schools are put on the homepage and people who are interested in ESD can see the tables.

Yanagawa Elementary School, which Tejima serves as the principal, is one of the school promoting initiatively ESD. Students learn about environmental issues, multicultural coexistence, human rights, living things and international cooperation. And the goal of learning is for students to develop problem solving skills, expressiveness and ability of positive action. All grade tables (ESD calendars) at Yanagawa Elementary School are arranged "the Period of Integrated Studies" in the center. These show that the period is the main part of ESD. The calendar for fourth grade students consists of environmental learning topics such as 'Garbage and us' (the Period of Integrated Studies) and 'Season and Creatures' (Science). In the table of fifth grade, we can see two topics environmental learning and living thing. Students learn environmental issues by 'Carbon minus Child Action' (the Period of Integrated Studies) and 'Mottai-nai (What a waste!)' (Moral Education), and they also think about leaving thing by 'Preparing to protect from earthquakes' (the Period of Integrated Studies) and 'Prevent natural disasters' (Social Studies). And the calendar of sixth grade show us some compound topics. Students learn about international understanding and cooperation such as 'Talk about the history and culture of Fukagawa town' (the Period of Integrated Studies) and 'Countries deeply connected to Japan' (society).

Each subject basically shows the unit of content related to the ESD topics in the calendar, but if the learning skills are involved, that unit is indicated. Therefore, the units of subjects not related to ESD such as Japanese, Mathematics and Music are described in the calendar, and are linked with other learning topics. This is an idea that all subjects and activities are related to ESD, and it is a basic concept that ESD practices are conducted by whole school approach. The learning topics of the Period of Integrated Studies can be decided at each school, so what kind of topics to set at the period is the key to promoting ESD. Then, in terms of the consultation, the main topics are set for each grade and learning contents are arranged in a well-balanced manner, so that teachers can put development of students in perspective. And the ESD 
calendar of Yanagawa Elementary school has been renewed to become a more effective curriculum. By creating new tables including learning objectives of each topic, lesson hours required for learning, main activities and sharing of human resources, even if teachers change, the continuity of ESD practices are able to keep. The ESD calendar is a 'persuasive model visibly showing that it can be most effectively promoted by the whole school approach.'

Resources within the school are not enough to do ESD practice. In order to acquire global perspectives and form the ability to proactively engage in immediate environments, students are required to meet diverse people and experience richly. Therefore, it is indispensable for schools to collaborate with external organizations. The most familiar collaborators for schools and teachers are parents. For changes of awareness and behavior of students to environments, they have to experience not only activities of environmental ESD at school but also some practices at home. It is one of the most important things that school cooperates with parents.

What is next required is cooperation with community. In the case of Japan, public elementary and junior high schools adopt school district system. It is a system in which the school to be enrolled depends on where students live. For citizens living in the school district (region), the school is where there is a possibility to let their children go in the future, and where they attended before. For these reasons, community as school districts (areas) and elementary schools are relatively closely related. However, with the progress of urbanization, in school districts where movement of people become active, relationships between schools and community are getting thinner. When the new principal has moved at a school, he / she meets with the leader of the community association of the school district and requests cooperation with the school again. In recent years elderly people who live in the school district are working as volunteers to cooperate in educational activities. Such regional human resources are also beneficial for promoting ESD in schools.

There are cases that schools promoting ESD collaborate with various external organizations including local residents in community, and the case of Omuta city is remarkable and a good example of institutional cooperation of ESD.

Omuta city is located in the southernmost of Fukuoka Prefecture, in the western part of Japan, and a provincial city with a population of 120 thousand. The city once flourished in the coal chemical industry, but with the decline of the coal industry concerned about the decline of the regional economy, so that city has been promoting the creation and development of environment and recycling industry. In 1998, it was approved by the Ministry of Economy, Trade and Industry as 'Omuta Eco Town' and it was recycled as 'Environment Recycle City.' And then, the coal mine heritage of Omuta city, including 
other areas in Northern Kyushu and Yamaguchi, was registered as a World heritage Site in 2015.On the other hand, among the more than 100,000 cities across the country, it is a region with a high population decline rate and aging rate.

Omuta city is called 'the town of UNESCO Schools' because all the public schools in the city are approved as schools of ASPNet. Generally, each school that wishes to join takes procedures for approval when joining the school network. The Omuta City Board of Education had made all public school that the city manage join the ASPNet. It was because it tried to promote ESD in the entire region.

In spreading ESD, Omuta City built the 'Omuta ESD Consortium' as an ESD promotion project for global human resources development. This consortium is a combination of 31 institutions that supports ESD of school in Omuta city, and belongs to various organizations such as social education facilities, local enterprises, environmental activity groups, NPOs and University.

One of elementary schools in Omuta city, Hayame Kita Elementary school, has created an ESD calendar and is making efforts to utilize conditions as an environment recycling city. The school also conducts the learning of world heritage because there is a Miyahara Mine (coal mine heritage) within the school district. Students in the sixth grade have learned about the heritage with cooperation from regional organi- zations and volunteer guides for tourist in Miyahara Mine. And by playing the role of tour guide as 'Child Guide,' the result of learning is demonstrated. The practices of learning world heritage have been maintained in this school.

Practices of Omuta City are not limited to the development of ESD at each school. The Omuta City Board of Education takes initiative and exchange between schools is underway. In Omuta City, workshop of ESD for teachers beyond schools and "Children's Summit" where students discuss environmental issues is held every year. Schools arrange staffs in charge of ASPNet in each school, organize a group of people in charge, and regularly discuss policies on information exchange and collaboration. In addition, the improvement of lesson is promoted by utilizing school network. The merits of all public schools in the city joining the ASPNet are to use the inter-school network on a daily basis and to share practical knowledge in education. The impact of teacher change is lessened and local human resources can also be shared.

In the case of Omuta City, further cooperation to schools by various stakeholders is made possible by constructing a consortium. Particularly, corporate participation is important for promoting ESD. As a member of the network, actively contributing enterprises to the social environment is the key to creating a sustainable society. In addition, by continuously addressing ESD with city (region), it can be expected transfor- 
mations of awareness and behavior of adults who encourage themselves to the environment.

ESD of schools in Japan is promoted mainly by UNESCO schools. What is common in advanced cases is that schools create curriculums in which other topics are well-balanced while placing the environment as main topic. And it is also common that schools and board of education are trying to develop conditions for teachers who practice ESD, sharing lesson plans, human resources and information, and enrichment of workshop. In addition, the consortium is also suggestive for creating regional bases (ESCs) on ESD.

The new curriculum Guidelines advocates improving learning to realize 'subjective learning,' 'interactive learning' and 'deep learning.' These methods of learning are also methods of learning ESD. Considering how to approach ESD learning topics (learning method) leads to how to engage in the creation of a 'sustainable society) (method of construction). ESD of schools in Japan is entering the next stage.

\section{REFERENCE}

Ichikawa, S. 2017, SDGs and environmental education, Gakubunsha

Ichikawa, S.2016, Environmental Education History in Japan, Minerva Shobo

Ichise, T. 2013, Research on the acceptance of UNESCO's values and principles in school education, Bulletin of Miyagi University of Education 48

Kobayashi, R. 2014, UNESCO School, Akashi Shoten
Kodama, T. 2015, Discussion of "Ability upbringing theory" in the school ESD practice, environmental education Vol. 21

Kodama, T. 2017, Environmental Education Formal Education in Japan, environmental education Vol. 26

Nonaka, M. 2014, ESD practice utilizing modernized industrial heritage and its development, Master's thesis

ASPNet in Japan, List of UNESCO Associated Schools

http://www.unesco-school.mext.go.jp/ esd/ (confirmed on November 24, 2017)

Cabinet Office, 2014, Public opinion poll on education for sustainable development (ESD)

https:// survey.gov-online.go.jp/ tokubetu/h26/h26-esd.pdf (confirmed on November 20, 2076)

Japan UNESCO Domestic Committee, 2016, ESD Promotion Guide (first edition)

http://www.mext.go.jp/component/a_ menu/other/micro_detail/_ icsFiles/afield-file /2017/05/31/1369326_01_3. pdf (confirmed on November 20, 2017)

Ministry of Education, Culture, Sports, Science and Technology, Central Education Council, 1999, Future Environmental Education / Environmental Learning - Towards a Sustainable Society

https: / / www.env.go.jp/council/former/tousin/039912-1.html (con- 
firmed on December 1, 2017)

Ministry of Education, Culture, Sports, Science and Technology, 2017, Curriculum guidelines for Elementary school and for Junior High School

Ministry of Economy, Trade and Industry, 2013, the future of learning that changes with ESD

https://edu.env.go.jp/esd/column/109 (confirmed on December 10, 2017)
UNESCO - Asian Culture Center (ACCJ), 2009, ESD Educational Materials Application Guide, UNE$\mathrm{SCO} \bullet$ Asian Cultural Center

Yanagawa Elementary school HP (confirmed on December 1, 2017)

Online journal

Journal of Sustainable Development Education on Research (JSDER) 